\title{
Targeting integrins in malignant glioma
}

\author{
Ghazaleh Tabatabai • Michael Weller • Burt Nabors • \\ Martin Picard • David Reardon • Tom Mikkelsen • \\ Curzio Ruegg $\cdot$ Roger Stupp
}

Received: 11 August 2010 /Accepted: 12 August 2010 /Published online: 4 September 2010

(C) Springer-Verlag 2010

\begin{abstract}
The integrin family of cell adhesion receptors is emerging as a promising target of anticancer therapy. AlphaVbeta3 and alphaVbeta5 integrins are overexpressed on both glioma cells and tumor vasculature. Cilengitide, the most advanced specific integrin inhibitor in oncology, has shown antitumor activity against glioma in early clinical trials. Durable remissions have been observed in phase I and phase II trials for recurrent glioblastoma (GBM) with both lower and higher doses of cilengitide. Pilot trials in newly diagnosed glioblastoma in conjunction with standard chemoradiotherapy have been encouraging. Preclinical data suggest synergy with concomitant chemo- and radiation therapy. A pivotal phase III study (CENTRIC) in newly diagnosed GBM patients is currently recruiting. This paper
\end{abstract}

G. Tabatabai $(\varangle) \cdot$ M. Weller

Department of Neurology, University Hospital Zurich,

Frauenklinikstrasse 26,

8091 Zurich, Switzerland

e-mail: ghazaleh.tabatabai@usz.ch

M. Weller

e-mail: michael.weller@usz.ch

B. Nabors

Department of Neurology, University of Alabama at Birmingham,

Birmingham, AL, USA

M. Picard

Global Clinical Development Unit Oncology, Merck KGaA,

Frankfurter Strasse 250,

64293 Darmstadt, Germany

D. Reardon

Departments of Surgery and Pediatrics, The Preston Robert Tisch

Brain Tumor Center, Duke University Medical Center,

Durham, NC, USA

T. Mikkelsen

Department of Neurosurgery, Hermelin Brain Tumor Center,

Henry Ford Hospital,

Detroit, MI, USA summarizes the current understanding of the role of integrins and their inhibition in gliomagenesis. The background and design of ongoing trials are outlined.

Keywords Integrins · Angiogenesis · Glioma ·

Glioblastoma $\cdot$ Clinical trials $\cdot$ Review

\section{Introduction}

Integrins are heterodimeric transmembrane cell surface receptors that play a key role in the crosstalk between the cell and its surrounding stroma [1]. Twenty-four different integrins have been identified to date. Integrins link the

\section{T. Mikkelsen}

Department of Neurology, Hermelin Brain Tumor Center,

Henry Ford Hospital,

Detroit, MI, USA

\section{Ruegg}

Division of Experimental Oncology, Centre Pluridisciplinaire d'Oncologie, Faculty of Biology and Medicine,

University of Lausanne, and NCCR Molecular Oncology

ISREC-EPFL,

Epalinges, Switzerland

C. Ruegg

Pathology, Med3, Department of Medicine, Faculty of Science, University of Fribourg,

Fribourg, Switzerland

\section{R. Stupp $(\bowtie)$}

Department of Neurosurgery, Centre Hospitalier Universitaire

Vaudois (CHUV) and University of Lausanne,

Lausanne, Switzerland

e-mail: roger.stupp@chuv.ch 
cytoskeleton to the extracellular matrix, and are recognized to be key regulators of tissue structure. Integrins regulate cell adhesion, migration, differentiation, proliferation, and survival during physiological and pathological conditions, including inflammation and cancer. Upon ligation to extracellular ligands (i.e., matrix proteins such as collagens, laminins, vitronectins and fibronectins), integrins activate downstream signaling pathways in concert with growth factor receptors, including platelet-derived growth factor receptor (PDGFR), epidermal growth factor receptor (EGFR) and vascular endothelial growth factor receptor (VEGFR).

Preclinical data indicate that integrins play a key role in cancer initiation and progression [2]. They provide adhesive, migratory, and survival cues to tumor cells and to cells of the tumor microenvironment, including angiogenic endothelial cells. The integrins alphaVbeta3 and alphaVbeta5, among others, are highly expressed not only on the tumor vasculature and angiogenic endothelial cells, but also on tumor cells, including gliomas (reviewed in $[3,4]$ ). Consequently, integrins have been considered as a promising therapeutic target in cancer [5]. Monoclonal antibodies and peptide-based integrin inhibitors are being investigated for their potential therapeutic activity in various tumor types. This strategy is in advanced stage clinical development in glioblastoma, a highly vascular primary brain tumor. The only integrin inhibitor being studied in glioma is cilengitide, we therefore focus this short review on this agent.

\section{Preclinical data on integrins in glioma}

In high-grade glioma, and in particular in glioblastoma, overexpression of alphaVbeta3 integrin is well documented. Importantly, alphaVbeta3 integrin is expressed both on angiogenic endothelial cells and on tumor cells [6-8]. Molecular imaging of alphaVbeta3 expression using the tracer $[18 \mathrm{~F}]$ Galacto-RGD and validation by immunohistochemistry revealed that alphaVbeta 3 integrin expression was mainly confined to the tumor region and was absent in normal tissue [9]. Selective alphaVbeta3 upregulation in malignant gliomas suggests that integrin signaling in glioblastoma has important functions. Emerging evidence indicates that integrins promote glioblastoma adhesion, migration and angiogenesis $[10,11]$. In an autocrine loop hypoxia will recruit alphaVbeta3 and alphaVbeta5 integrins and activate focal adhesion kinase (FAK). Integrin inhibition decreases hypoxia-inducible factor 1alpha (HIF1alpha) and reduces thus tumor hypoxia, which may lead to increased radiation sensitivity [12].

The integrin alpha6betal plays an important role for the regulation of glioma-initiating cells in the perivascular niche [13]. This integrin mediates the interaction of glioma-initiating cells to laminin, an extracellular matrix protein expressed in basement membranes, including those supporting endothelial cells. This interaction provides an anchorage for glioma-initiating cells within the perivascular niche and supports their tumorigenic potential.

Given the role of integrins in promoting glioma growth, invasion and angiogenesis, integrin inhibitors might be ideal therapeutic tools with synergistic activities in conjunction with already established therapeutic modalities, i.e., radiation therapy and cytotoxic chemotherapy. Importantly, because of their antiangiogenic effects [14], integrin inhibitors are expected to normalize the tumor vasculature, which in turn might enhance the effects of radiation therapy and chemotherapy. Indeed the efficacy of these two therapeutic modalities depends on an effective blood perfusion for oxygenation of the tumor (i.e., an important condition for radiation-induced tumor cell killing) and optimal drug delivery. Inhibition of alphaVbeta3 and alphaVbeta5 integrins in hypoxic glioma cells by siRNA decreases HIF-1alpha by regulating FAK. Silencing this signaling cascade in established xenografts indeed reduced hypoxia and decreased angiogenesis [12].

Interestingly, ionizing radiation induces ceramidemediated apoptosis of tumor endothelial cells, causing tumor vessel disruption and delayed tumor growth [15]. Consistent with a cytotoxic effect of radiotherapy on angiogenic vessels, concomitant administration of antiangiogenic drugs decreases endothelial cell survival. Anti-VEGF antibodies (e.g., bevacizumab) [16], VEGFR inhibitors (e.g., AG013736) [17], mTOR inhibitors (e.g., RAD001) [18], and integrin inhibition (cilengitide) [19] sensitize angiogenic endothelial cells to ionizing radiation-induced death, thereby enhancing tumor vascular damage induced by radiotherapy and improving therapeutic response [20]. Irradiation of glioma cells increases their expression of alphaVbeta3 integrin [21], thus integrin inhibition will further synergize with radiation therapy.

Regarding clinical translation, targeting alphavbeta 3 and alphavbeta5 might reduce hypoxia and thus resistance to radio- and/or chemotherapy [12]. Indeed, arresting integrin signaling synergistically enhances the anti-glioma effect of radiation therapy in vivo [22].

A recent preclinical study suggests that low concentrations of small molecular integrin inhibitors used as single agents may stimulate angiogenesis and tumor growth in experimental melanoma and Lewis Lung carcinoma models, through increased VEGF expression and VEGFR2 signaling [23]. The concentrations of the small molecular integrin inhibitor cilengitide, measured in patients in clinical trials, however, largely exceed the critical "proangiogenic" concentrations described in this preclinical study, and therefore, paradoxical proangiogenic effects of small 
molecular integrin inhibitors in the clinical application seem rather unlikely [24]. In fact, relative cerebral blood volume and blood flow, measured by perfusion MRI, remained stable or decreased among recurrent GBM patients responding to cilengitide therapy in a prior phase I study [25]. Durable and clinically relevant responses have been observed with cilengitide monotherapy; ongoing clinical studies administer cilengitide in combination with radiotherapy and/or chemotherapy. Nevertheless, the durable therapeutic success will depend on the efficient management of escape mechanisms occurring under antiintegrin therapies $[26,27]$.

\section{Integrin inhibition attenuates invasion and metastasis secondary to radiation-induced angiogenesis inhibition}

Vascular normalization may not be the only mechanism by which integrin inhibitors synergize with radiochemotherapy. We have recently observed that high doses of ionizing radiation locally suppress angiogenesis in vivo and inhibited endothelial cell sprouting in vitro through a cell-autonomous effect mediated by the TGFbeta receptor ALK5 [28]. Tumors derived from oral squamous cell carcinoma and from hepatoma cell lines growing within a pre-irradiated bed had decreased microvascular density and were smaller, but their margins were highly invasive. They also had increased hypoxia and necrosis, and a more aggressive behavior with a higher number of lung metastases [29]. Thus, pre-irradiation of the tumor bed reduces local tumor growth, likely due to acute metabolic starvation secondary to suppressed angiogenesis, but at the same time it may enhance local invasion and metastatic spreading, possibly through increased hypoxia. We have identified the cysteine-rich protein 61 (CYR61), a member of the CCN (CYR61/CTGF/NOV) family of matricelluar proteins regulating cell growth, differentiation, survival and migration in development, tissue remodeling and repair [30], and integrin alphaVbeta5 (a receptor for CYR61) expressed by tumor cells, as critical molecules that cooperate to promote local invasion and distant metastases [29]. Importantly, function-blocking anti- $\alpha \mathrm{V}$ mAb 17E6 [29, 31] and cilengitide-inhibited CYR61-mediated invasion and metastasis formation of tumor cells growing in a pre-irradiated bed. These results suggest that cilengitide may improve cancer control in conjunction with radiotherapy by attenuating some of the unwanted rebound effect of radiation-induced inhibition of angiogenesis. Hypoxia is well known to activate pro-invasive programs [32] and select for resistant variants with invasive characteristics. This view is consistent with a recent experimental study demonstrating that selected inhibition of tumor angiogenesis by antiangiogenic drugs, including in experimental glioma, results in increased invasion and metastasis formation [33].

\section{Cilengitide}

Cilengitide (Merck KGaA, Darmstadt, Germany) is a synthetic Arg-Gly-Asp (RGD) pentapeptide recognizing the RGD ligand-binding motif (ligand binding site) on the integrin receptors alphaVbeta3 and alphaVbeta5 [34, 35] and competitively blocks integrin ligand binding. It was shown to diminish angiogenesis in vitro [36]. In an important early preclinical study, cilengitide markedly suppressed tumor growth in a medulloblastoma and orthotopic glioblastoma models (i.e., tumors were grown in the brain), while no growth inhibition was demonstrated in a heterotopic model (i.e., when tumors were grown in the flank of nude mice), or when an inactive peptide was used [37]. This suggests that the brain environment is particularly susceptible to integrin inhibition and led to subsequent clinical investigation.

In phase I studies cilengitide was administered twice weekly by intravenous infusion over $1 \mathrm{~h}$. No dose limiting toxicity was observed with doses up to $2400 \mathrm{mg} / \mathrm{m}^{2}$. Peak plasma concentrations that had shown antitumor effects in preclinical models were achieved at doses $\geq 120 \mathrm{mg} / \mathrm{m} 2[25$, $38-40]$. The terminal half-life of cilengitide is $3-5 \mathrm{~h}$, suggesting the possibility of increased efficacy with a more frequent administration or continuous infusion schedule.

\section{Clinical experience with cilengitide in malignant glioma}

Sustained responses in recurrent glioblastoma were seen both with lower and higher doses of cilengitide as single agent in two phase I trials in adult and pediatric patients $[25,39]$. Overall cilengitide was well tolerated, a maximal tolerated dose not reached and a clinical benefit seen both at higher and lower doses. Subsequent trials were initiated with flat (not per $\mathrm{m}^{2}$ ) twice weekly dosing of cilengitide at an intermediate lower $(500 \mathrm{mg})$ and intermediate higher $(2000 \mathrm{mg})$ dose (Table 1). In a randomized phase II trial of 81 patients with recurrent glioblastoma, treatment was administered at the lower and higher dose. Cilengitide monotherapy was well tolerated independently of the dose. Objective responses were achieved in $5 \%$ or $13 \%$ of patients treated with $500 \mathrm{mg}$ or $2000 \mathrm{mg}$, respectively. Progression-free survival after 6 months was $10 \%$ and $15 \%$, whereas overall survival was in the range of 6.5 versus 9.9 months, respectively [41]. Recently, long-term survival results were reported demonstrating a 4-year survival rate of $2.4 \%(95 \% \mathrm{CI} 0.2 ; 11 \%)$ in patients treated with the lower dose, and $10.0 \%(95 \%$ CI $3.2 ; 21.5 \%)$ in patients 


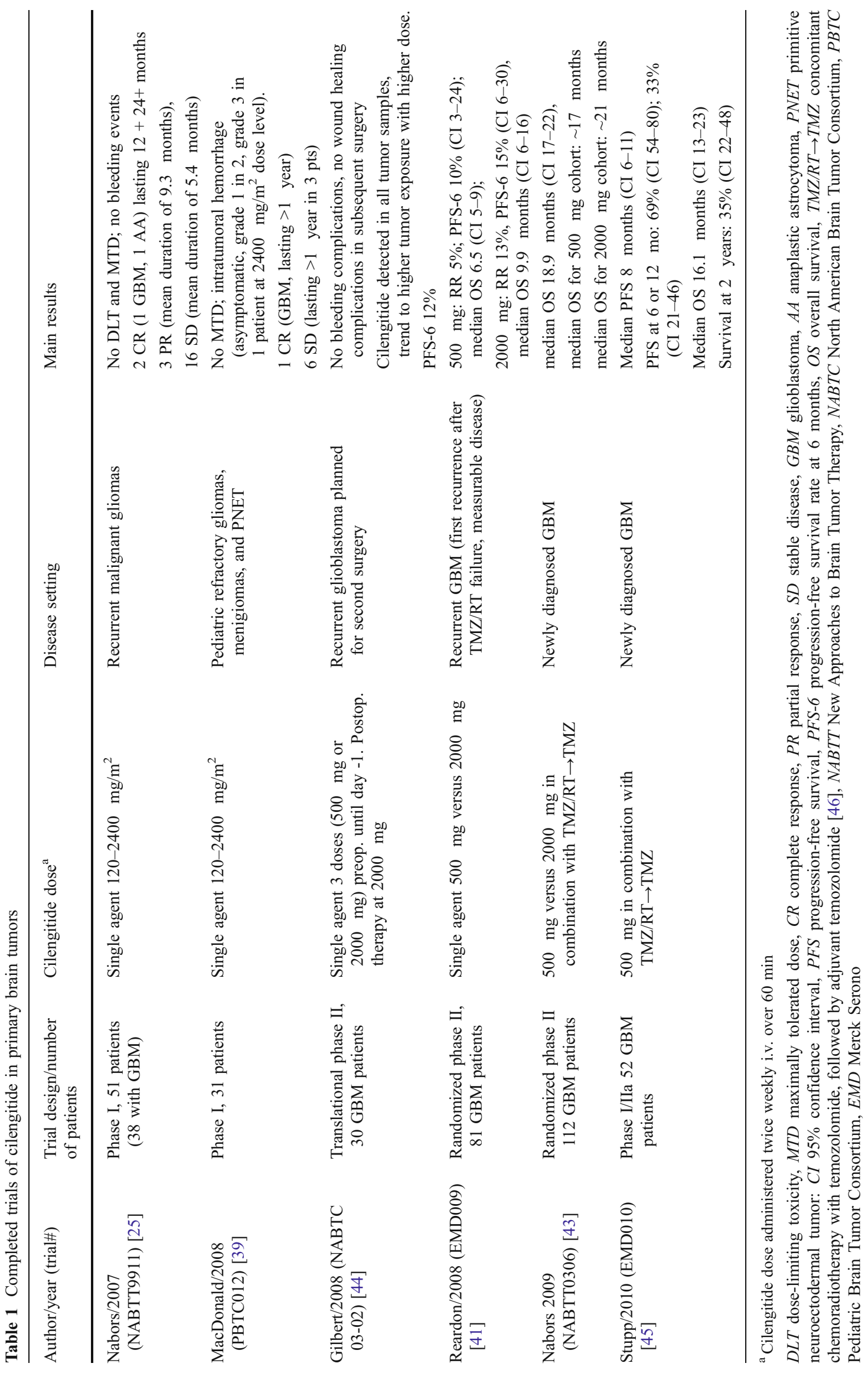


treated with the higher dose of cilengitide [42]. Similarly, a phase II randomized trial evaluating lower $(500 \mathrm{mg})$ and higher $(2000 \mathrm{mg}$ ) doses cilengitide added to temozolomide and radiotherapy (TMZ/RT) in newly diagnosed glioblastoma patients was reported in abstract form [43]. Median survival was 18.9 months, with an estimated median survival of 17 months and 21 months, for the lower and higher dose, respectively. Finally, higher exposure of the tumor tissue could be demonstrated in another randomized trial evaluating 3 doses of either $500 \mathrm{mg}$ or $2000 \mathrm{mg}$ cilengitide prior to tumor resection in recurrent disease. Cilengitide concentrations were several-fold higher in the tumor than the corresponding plasma concentrations, demonstrating both excellent penetration through the blood-tumor barrier and retention within the tumor. Importantly, safety could be confirmed and no increase in bleeding complications or wound healing problems were observed [44].

Consistently, the higher dose of cilengitide is favored by exposure, responses, progression-free and overall survival.

Based on a strong preclinical rationale of radiosensitization and synergy with both cilengitide and irradiation and TMZ, we designed in parallel to the above-mentioned trials a phase II pilot trial of adding cilengitide $(500 \mathrm{mg})$ to standard chemoradiotherapy with TMZ (TMZ/RT $\rightarrow$ TMZ) $[45,46]$.

In a multicenter pilot study on 52 patients, treatment was well tolerated with no identifiable added toxicity. The primary endpoint of progression-free survival at 6 months compared favorably with historical controls $(69 \%$ versus $54 \%)$ [46, 47]. Median survival was 16.1 months, with a 2-year survival rate of $35 \%$ [45]. Interestingly, the outcome was particularly good in patients with a methylated $\mathrm{O}^{6}$-methylguanine-DNA methyltransferase (MGMT) gene promoter, Such patients were previously identified to particularly benefit from TMZ chemotherapy [48]. This is consistent with the working hypothesis, that antiangiogenic therapy may lead to normalization of tumor vasculature, decrease of hypoxia, improved drug delivery and enhanced cytotoxicity. In addition, the currently used higher dose of $2000 \mathrm{mg}$ should also exert relevant direct antitumor activity and directly synergize with standard chemoradiotherapy.

Building on our pilot experience and the consistent encouraging results of the other clinical trials in malignant glioma, Merck KGaA in collaboration with the European Organisation for Research and Treatment of Cancer (EORTC) and the Canadian Brain Tumor Consortium is sponsoring a large prospective clinical phase III trial (CENTRIC study, Fig. 1) [49]. Based on the suggested synergy between normalized perfusion and active chemotherapy, only patients with a methylated $M G M T$ are eligible.
This requires centralized upfront $M G M T$ testing, and it is the first prospective international clinical oncology trial incorporating this novel molecular marker to homogenously define the treated patient population. Other changes from the previous phase II trial are the exclusive use of the higher dose of cilengitide $(2000 \mathrm{mg})$, and cilengitide maintenance therapy for up to 18 months. In parallel a separate 3-arm randomized phase II trial has been designed for patients with MGMT unmethylated tumors (CORE study). Here an intensified high-dose daily cilengitide administration before radiotherapy is being explored. Early data indicate that this schedule is well tolerated and safe, and the trial is now ongoing in a multicenter setting. The results of all completed brain tumor clinical trials using cilengitide are summarized in Table 1.

\section{Conclusions}

The ongoing phase III CENTRIC trial is successfully recruiting in a multi-national setting and is expected to be completed by the end of the year 2010. Careful analysis of data emerging from this trial will make an important contribution to further defining the role on integrin inhibition in malignant gliomas. The absence of significant toxicity and excellent tolerance will allow to safely testing integrininhibition in combination with other targeted and cytotoxic agents. Combined inhibition of integrins and VEGF may lead to further enhancement and increased antitumor effect, and clinical evaluation of this concept is warranted.

Conflict of interest statement The authors have no significant conflict of interest to declare. The paper was written by G. Tabatabai and R. Stupp, with review, input, comments and final approval by all authors. The authors have conducted and are conducting industry and/ or NCI-sponsored trials with cilengitide.

\section{References}

1. Takada Y, Ye X, Simon S (2007) The integrins. Genome Biol 8 (5):215. doi:10.1186/gb-2007-8-5-215

2. Desgrosellier JS, Cheresh DA (2010) Integrins in cancer: biological implications and therapeutic opportunities. Nat Rev Cancer 10(1):9-22. doi:10.1038/nrc2748

3. Ruegg C, Mariotti A (2003) Vascular integrins: pleiotropic adhesion and signaling molecules in vascular homeostasis and angiogenesis. Cell Mol Life Sci 60(6):1135-1157

4. Avraamides CJ, Garmy-Susini B, Varner JA (2008) Integrins in angiogenesis and lymphangiogenesis. Nat Rev Cancer 8(8):604617. doi: $10.1038 / \mathrm{nrc} 2353$

5. Alghisi GC, Ruegg C (2006) Vascular integrins in tumor angiogenesis: mediators and therapeutic targets. Endothelium 13 (2):113-135

6. Schnell O, Krebs B, Wagner E, Romagna A, Beer AJ, Grau SJ, Thon N, Goetz C, Kretzschmar HA, Tonn JC, Goldbrunner RH 
(2008) Expression of integrin alphavbeta3 in gliomas correlates with tumor grade and is not restricted to tumor vasculature. Brain Pathol 18(3):378-386. doi:10.1111/j.1750-3639.2008.00137.x

7. Taga T, Suzuki A, Gonzalez-Gomez I, Gilles FH, Stins M, Shimada H, Barsky L, Weinberg KI, Laug WE (2002) Alpha vintegrin antagonist emd 121974 induces apoptosis in brain tumor cells growing on vitronectin and tenascin. Int J Cancer 98(5):690697. doi:10.1002/ijc. 10265

8. Bello L, Francolini M, Marthyn P, Zhang J, Carroll RS, Nikas DC, Strasser JF, Villani R, Cheresh DA, Black PM (2001) Alpha(v) beta3 and alpha(v)beta5 integrin expression in glioma periphery. Neurosurgery 49(2):380-389, discussion 390

9. Beer AJ, Haubner R, Sarbia M, Goebel M, Luderschmidt S, Grosu AL, Schnell O, Niemeyer M, Kessler H, Wester HJ, Weber WA, Schwaiger M (2006) Positron emission tomography using [18f]galacto-rgd identifies the level of integrin alpha(v)beta3 expression in man. Clin Cancer Res 12(13):3942-3949. doi:10.1158/1078-0432.CCR-06-0266

10. Wild-Bode C, Weller M, Wick W (2001) Molecular determinants of glioma cell migration and invasion. J Neurosurg 94(6):978984. doi:10.3171/jns.2001.94.6.0978

11. Maurer GD, Tritschler I, Adams B, Tabatabai G, Wick W, Stupp R, Weller M (2009) Cilengitide modulates attachment and viability of human glioma cells, but not sensitivity to irradiation or temozolomide in vitro. Neuro Oncol 11(6):747-756. doi:10.1215/15228517-2009-012

12. Skuli N, Monferran S, Delmas C, Favre G, Bonnet J, Toulas C, Cohen-Jonathan Moyal E (2009) Alphavbeta3/alphavbeta5 integrins-fak-rhob: a novel pathway for hypoxia regulation in glioblastoma. Cancer Res 69(8):3308-3316. doi:10.1158/00085472.CAN-08-2158

13. Lathia JD, Gallagher J, Heddleston JM, Wang J, Eyler CE, Macswords J, Wu Q, Vasanji A, McLendon RE, Hjelmeland AB, Rich JN (2010) Integrin alpha 6 regulates glioblastoma stem cells. Cell Stem Cell 6(5):421-432. doi:10.1016/j.stem.2010.02.018

14. Ruegg C, Alghisi GC (2010) Vascular integrins: therapeutic and imaging targets of tumor angiogenesis. Recent Results Cancer Res 180:83-101. doi:10.1007/978-3-540-78281-0 6

15. Garcia-Barros M, Paris F, Cordon-Cardo C, Lyden D, Rafii S, Haimovitz-Friedman A, Fuks Z, Kolesnick R (2003) Tumor response to radiotherapy regulated by endothelial cell apoptosis. Science 300(5622):1155-1159. doi:10.1126/science.1082504300/ $5622 / 1155$

16. Nieder C, Wiedenmann N, Andratschke NH, Astner ST, Molls M (2007) Radiation therapy plus angiogenesis inhibition with bevacizumab: rationale and initial experience. Rev Recent Clin Trials 2(3): 163-168

17. Fenton BM, Paoni SF (2007) The addition of ag-013736 to fractionated radiation improves tumor response without functionally normalizing the tumor vasculature. Cancer Res 67(20):99219928. doi:10.1158/0008-5472.CAN-07-1066

18. Shinohara ET, Cao C, Niermann K, Mu Y, Zeng F, Hallahan DE, Lu B (2005) Enhanced radiation damage of tumor vasculature by mtor inhibitors. Oncogene 24(35):5414-5422. doi:10.1038/sj. onc. 1208715

19. Albert JM, Cao C, Geng L, Leavitt L, Hallahan DE, Lu B (2006) Integrin alpha $\mathrm{v}$ beta 3 antagonist cilengitide enhances efficacy of radiotherapy in endothelial cell and non-small-cell lung cancer models. Int J Radiat Oncol Biol Phys 65(5):1536-1543. doi:10.1016/j.ijrobp.2006.04.036

20. Wachsberger P, Burd R, Dicker AP (2004) Improving tumor response to radiotherapy by targeting angiogenesis signaling pathways. Hematol Oncol Clin North Am 18(5):1039-1057. doi:10.1016/j.hoc.2004.06.007, viii

21. Wild-Bode C, Weller M, Rimner A, Dichgans J, Wick W (2001) Sublethal irradiation promotes migration and invasiveness of glioma cells: implications for radiotherapy of human glioblastoma. Cancer Res 61(6):2744-2750

22. Mikkelsen T, Brodie C, Finniss S, Berens ME, Rennert JL, Nelson K, Lemke N, Brown SL, Hahn D, Neuteboom B, Goodman SL (2009) Radiation sensitization of glioblastoma by cilengitide has unanticipated schedule-dependency. Int J Cancer 124(11):27192727. doi: $10.1002 /$ ijc. 24240

23. Reynolds AR, Hart IR, Watson AR, Welti JC, Silva RG, Robinson SD, Da Violante G, Gourlaouen M, Salih M, Jones MC, Jones DT, Saunders G, Kostourou V, Perron-Sierra F, Norman JC, Tucker GC, Hodivala-Dilke KM (2009) Stimulation of tumor growth and angiogenesis by low concentrations of RGD-mimetic integrin inhibitors. Nat Med 15(4):392-400. doi:10.1038/nm.1941

24. Weller M, Reardon D, Nabors B, Stupp R (2009) Will integrin inhibitors have proangiogenic effects in the clinic? Nat Med 15 (7):726. doi:10.1038/nm0709-726, author reply 727

25. Nabors B, Mikkelsen T, Rosenfeld S, Hochberg F, Shastry Akella N, Fisher J, Cloud G, Zhang Y, Carson K, Wittemer S, Colvevas D, Grossman S, for the NABTT CNS Consortium (2007) A phase I and correlative biology study of cilengitide in patients with recurrent malignant glioma. J Clin Oncol 25(13):1651-1657

26. Abdollahi A, Griggs DW, Zieher H, Roth A, Lipson KE, Saffrich R, Grone HJ, Hallahan DE, Reisfeld RA, Debus J, Niethammer AG, Huber PE (2005) Inhibition of alpha(V)beta3 integrin survival signaling enhances antiangiogenic and antitumor effects of radiotherapy. Clin Cancer Res 11(17):6270-6279

27. Abdollahi A, Folkman J (2010) Evading tumor evasion: current concepts and perspectives of anti-angiogenic cancer therapy. Drug Resist Updat 13(1-2):16-28. doi:10.1016/j.drup.2009.12.001

28. Imaizumi N, Monnier $\mathrm{Y}$, Hegi M, Mirimanoff RO, Ruegg $\mathrm{C}$ (2010) Radiotherapy suppresses angiogenesis in mice through tgfbetari/alk5-dependent inhibition of endothelial cell sprouting. PLoS ONE 5(6):e11084. doi:10.1371/journal.pone.0011084

29. Monnier Y, Farmer P, Bieler G, Imaizumi N, Sengstag T, Alghisi GC, Stehle JC, Ciarloni L, Andrejevic-Blant S, Moeckli R, Mirimanoff RO, Goodman SL, Delorenzi M, Ruegg C (2008) Cyr61 and alphaVbeta5 integrin cooperate to promote invasion and metastasis of tumors growing in preirradiated stroma. Cancer Res 68(18):7323-7331. doi:10.1158/0008-5472.CAN-08-0841

30. Leask A, Abraham DJ (2006) All in the ccn family: essential matricellular signaling modulators emerge from the bunker. J Cell Sci 119(Pt 23):4803-4810. doi:10.1242/jcs.03270

31. Mitjans F, Sander D, Adan J, Sutter A, Martinez JM, Jaggle CS, Moyano JM, Kreysch HG, Piulats J, Goodman SL (1995) An antialpha V-integrin antibody that blocks integrin function inhibits the development of a human melanoma in nude mice. J Cell Sci 108 (Pt 8):2825-2838

32. Chan DA, Giaccia AJ (2007) Hypoxia, gene expression, and metastasis. Cancer Metastasis Rev 26(2):333-339. doi:10.1007/ s10555-007-9063-1

33. Paez-Ribes M, Allen E, Hudock J, Takeda T, Okuyama H, Vinals F, Inoue M, Bergers G, Hanahan D, Casanovas O (2009) Antiangiogenic therapy elicits malignant progression of tumors to increased local invasion and distant metastasis. Cancer Cell 15 (3):220-231. doi:10.1016/j.ccr.2009.01.027

34. Xiong JP, Stehle T, Zhang R, Joachimiak A, Frech M, Goodman SL, Arnaout MA (2002) Crystal structure of the extracellular segment of integrin alphaVbeta3 in complex with an arg-gly-asp ligand. Science 296(5565):151-155. doi:10.1126/science1069040

35. Goodman SL, Holzemann G, Sulyok GA, Kessler H (2002) Nanomolar small molecule inhibitors for alphaV(beta)6, alphaV (beta)5, and alphaV(beta)3 integrins. J Med Chem 45(5):10451051. doi:jm0102598

36. Nisato RE, Tille JC, Jonczyk A, Goodman SL, Pepper MS (2003) AlphaV beta 3 and alphav beta 5 integrin antagonists inhibit 
angiogenesis in vitro. Angiogenesis 6(2):105-119. doi:10.1023/B: AGEN.0000011801.98187.f25255607

37. MacDonald TJ, Taga T, Shimada H, Tabrizi P, Zlokovic BV, Cheresh DA, Laug WE (2001) Preferential susceptibility of brain tumors to the antiangiogenic effects of an alpha(V) integrin antagonist. Neurosurgery 48(1):151-157

38. Eskens FA, Dumez H, Hoekstra R, Perschl A, Brindley C, Bottcher S, Wynendaele W, Drevs J, Verweij J, van Oosterom AT (2003) Phase I and pharmacokinetic study of continuous twice weekly intravenous administration of cilengitide (EMD 121974), a novel inhibitor of the integrins alphavbeta3 and alphavbeta5 in patients with advanced solid tumours. Eur J Cancer 39(7):917926. doi:S0959804903000571

39. MacDonald TJ, Stewart CF, Kocak M, Goldman S, Ellenbogen RG, Phillips P, Lafond D, Poussaint TY, Kieran MW, Boyett JM, Kun LE (2008) Phase I clinical trial of cilengitide in children with refractory brain tumors: pediatric brain tumor consortium study pbtc-012. J Clin Oncol 26(6):919-924. doi:10.1200/ JCO.2007.14.1812

40. Stupp R, Ruegg C (2007) Integrin inhibitors reaching the clinic. J Clin Oncol 25(13):1637-1638

41. Reardon DA, Fink KL, Mikkelsen T, Cloughesy TF, O’Neill A, Plotkin S, Glantz M, Ravin P, Raizer JJ, Rich KM, Schiff D, Shapiro WR, Burdette-Radoux S, Dropcho EJ, Wittemer SM, Nippgen J, Picard M, Nabors LB (2008) Randomized phase II study of cilengitide, an integrin-targeting arginine-glycine-aspartic acid peptide, in recurrent glioblastoma multiforme. J Clin Oncol 26(34):5610-5617. doi:10.1200/JCO.2008.16.7510

42. Fink K, Mikkelsen T, Nabors LB, Ravin P, Plotkin SR, Schiff D, Hicking C, Picard M, Reardon DA (2010) Long-term effects of cilengitide, a novel integrin inhibitor, in recurrent glioblastoma: a randomized phase IIa study. Proc Am Soc Clin Oncol, J Clin Oncol 28(suppl): $15 \mathrm{~s}$, abstract 2010

43. Nabors L, Mikkelsen T, Batchelor T, Lesser G, Rosenfeld M, Ye X, Piantadosi S, Olson J, Brem S, Grossman S (2009) Nabtt 0306: A randomized phase II trial of EMD 121974 in conjunction with concomitant and adjuvant temozolomide with radiation therapy in patients with newly diagnosed glioblastoma multiforme (GBM). Proc Am Soc Clin Oncol, J Clin Oncol 27:15s, suppl; abstract 2001
44. Gilbert M, Lamborn K, Lassman A, Cloughesy T, Chang S, Lieberman F, Wen P, Poetzsch S, Picard M, Prados M, Kuhn J, for the North American Brain Tumor Consortium (2007) Tumor tissue delivery of cilengitide fater intravenous administration to patients with recurrent glioblastoma. Preliminary data from NABTC protocol 03-02. Neuro Oncol 4:525

45. Stupp R, Hegi ME, Neyns B, Goldbrunner R, Schlegel U, Clement PM, Grabenbauer GG, Ochsenbein AF, Simon M, Dietrich PY, Pietsch T, Hicking C, Tonn JC, Diserens AC, Pica A, Hermisson M, Krueger S, Picard M, Weller M (2010) Phase I/ IIa study of cilengitide and temozolomide with concomitant radiotherapy followed by cilengitide and temozolomide maintenance therapy in patients with newly diagnosed glioblastoma. J Clin Oncol 28(16):2712-2718. doi:10.1200/JCO.2009.26.6650

46. Stupp R, Mason WP, van den Bent MJ, Weller M, Fisher B, Taphoorn MJ, Belanger K, Brandes AA, Marosi C, Bogdahn U, Curschmann J, Janzer RC, Ludwin SK, Gorlia T, Allgeier A, Lacombe D, Cairncross JG, Eisenhauer E, Mirimanoff RO (2005) Radiotherapy plus concomitant and adjuvant temozolomide for glioblastoma. N Engl J Med 352(10):987-996

47. Stupp R, Hegi ME, Mason WP, van den Bent MJ, Taphoorn MJ, Janzer RC, Ludwin SK, Allgeier A, Fisher B, Belanger K, Hau P, Brandes AA, Gijtenbeek J, Marosi C, Vecht CJ, Mokhtari K, Wesseling P, Villa S, Eisenhauer E, Gorlia T, Weller M, Lacombe D, Cairncross JG, Mirimanoff RO (2009) Effects of radiotherapy with concomitant and adjuvant temozolomide versus radiotherapy alone on survival in glioblastoma in a randomised phase III study: 5 -year analysis of the EORTC-NCIC trial. Lancet Oncol 10 (5):459-466. doi:10.1016/S1470-2045(09)70025-7

48. Hegi ME, Diserens AC, Gorlia T, Hamou MF, de Tribolet N, Weller M, Kros JM, Hainfellner JA, Mason W, Mariani L, Bromberg JE, Hau P, Mirimanoff RO, Cairncross JG, Janzer RC, Stupp R (2005) MGMT gene silencing and benefit from temozolomide in glioblastoma. N Engl J Med 352(10):997-1003

49. Stupp R, Van Den Bent MJ, Erridge SC, Reardon DA, Hong Y, Wheeler H, Hegi M, Perry JR, Picard M, Weller M (2010) Cilengitide in newly diagnosed glioblastoma with MGMT promoter methylation: protocol of a multicenter, randomized, openlabel, controlled phase III trial (CENTRIC). Proc Am Soc Clin Oncol, J Clin Oncol 28:15s, suppl; abstr TPS152 